\title{
Growth hormone deficiency in patients with obesity
}

\author{
Roberto Salvatori ${ }^{1}$
}

Received: 24 February 2015/ Accepted: 2 March 2015/Published online: 10 March 2015

(C) Springer Science+Business Media New York 2015

It is well known that the growth hormone (GH)-insulin-like growth factor type I (IGF-I) axis-in addition to regulating somatic growth exerts important metabolic actions and regulates body composition [1]. GH (like insulin) is essential in adapting the utilization of calories to the amount of ingested food, promoting anabolism when caloric supply exceeds demands, and catabolism in the opposite situation. While insulin is the main metabolic hormone in the fed state, GH assumes a key role as stimulator of lipolysis during prolonged fasting, when it causes preferential oxidation of lipids and protein synthesis [2]. The increase in GH secretion that occurs with fasting may have represented an evolutionary advantage in times of food scarcity. However, GH and IGF-I have opposite effects on glucose homeostasis, with the former reducing insulin sensitivity (mainly acting in the liver) and the latter increasing it in the muscle.

The relationships between adipose tissue and $\mathrm{GH}$ secretion are complex. Obesity induces hyperinsulinemia, hypo-adiponectinemia, hyper-leptinemia, reduced serum ghrelin, and increased free fatty acid (FFA) levels, thereby suppressing GH secretion from the pituitary [3]. Thus, high prevalent conditions related to insulin resistance, such as visceral obesity, non-alcoholic hepatic disease, and type 2 diabetes, are associated with low GH secretion [3]. Because $\mathrm{GH}$ can contribute to insulin resistance that may develop when caloric supply exceeds demand, the reduction in GH secretion that occurs with obesity may be an

Roberto Salvatori

salvator@jhmi.edu

1 Division of Endocrinology, Diabetes and Metabolism, Johns Hopkins University School of Medicine, 1830 East Monument Street Suite \#333, Baltimore, MD 21287, USA adaptive phenomenon to prevent insulin resistance [3]. However, the reduction in GH secretion may further increase fat accumulation by reducing lipolysis, and therefore exacerbate obesity, establishing a dangerous vicious circle. Accordingly, truncal adiposity is one of the most important clinical findings of the adult GH deficiency (GHD) syndrome [4]. Despite this association, a reverse causal link between GHD and obesity has not been established.

Another important interaction between GH and adipose tissue relates to the activity of the $11 \beta$-hydroxy steroid dehydrogenase type 1 (11 $\beta$-HSD-1) enzyme, which catalyzes the conversion of inactive cortisone to active cortisol. Because GH (and/or IGF-I) inhibits 11 $\beta$-HSD-1 expression in adipose tissue (and liver), GHD causes increase in $11 \beta$-HSD-1 activity, thereby creating a local cortisol excess even when overall cortisol levels are normal [5].

Great attention has been paid in the last 2 decades on studying the consequences of adult onset GHD. This condition results in increased visceral adipose tissue, insulin resistance, and increased cardiovascular risk [4]. Conversely, the GH status of obese subjects is less well characterized. It is well known that the secretion of $\mathrm{GH}$ is markedly reduced in obese individuals compared to agematched controls [3]. Indeed, the $\mathrm{GH}$ response to a variety of stimuli is significantly blunted in obese subjects. Several mechanisms underlie this condition, including reduction of both frequency and amplitude of GH secretory bursts and increase in GH metabolic clearance [6]. Whether these changes are a simple and adaptive consequence of obesity, or they somehow contribute or worsen the excessive weight accumulation is not yet known.

In this issue of Endocrine Lubrano et al. [7] performed pituitary MRI and GH stimulation test (with GHRH + arginine) in a large number (184) of obese subjects 
$\left(\mathrm{BMI} \geq 30 \mathrm{~kg} / \mathrm{m}^{2}\right.$ ). Using a cutoff peak $\mathrm{GH}$ of $4.2 \mathrm{ng} / \mathrm{ml}$, they found a subnormal GH response in $38 \%$ (70/184) of the subjects. All but one of the 70 GHD subjects (99.5\%) had MRI image of empty sella (ES), while the same MRI feature was present in $54 \%(62 / 114)$ of subjects who were judged to be GH sufficient. GHD was therefore present in 69 of the total 131 ES subjects, with a prevalence of $52.6 \%$, similar to what previously reported [8]. However, a surprising finding in this paper is the very high overall prevalence of ES in obese subjects (131/184, $71 \%$ ). No obvious explanation of such high prevalence is offered, but a selection bias must have been present. Because of the high prevalence of ES in subjects with blunted GH response, the authors hypothesize that organic pituitary damage (i.e., the GHD status caused by ES) may have a role in the development of obesity, and that this scenario may open the possibility of future trials looking at the treatment of obesity with GH. Indeed, GH has become a common treatment in some forms of genetic obesity such a Prader Willi syndrome [9]. However, a recent meta-analysis of 982 obese individuals treated with GH showed a reduction in adipose mass, but not overall weight reduction [10]. The effect of GH treatment on insulin sensitivity is an important consideration, as many obese subjects have insulin resistance. The end effect of GH therapy on glucose metabolism is the result of two opposite effects: a favorable one (mediated by the body composition improvement) and a negative (directly caused by its counter-insular effect of $\mathrm{GH})$. The importance of GH in causing insulin resistance is highlighted by the observation that subjects with severe, lifetime, untreated isolated GHD are insulin sensitive despite an increased visceral fat [11]. Nevertheless, most studies show that the net effect of GH replacement (both in GHD and obese subjects) is a positive effect on insulin sensitivity, at least in the short term [3].

While several conditions without obvious GH deficiency are treated with GH replacement in childhood (e.g., Turner syndrome, renal insufficiency, idiopathic short stature), we need to differentiate the pharmacological effects of $\mathrm{GH}$ from replacement therapy. To do so, we need tools to accurately diagnose GHD. While pediatric endocrinologists have struggled for decades with the fallacy of stimulation tests, they are often rescued and guided in their "treat vs. not treat" decision by the ultimate effect of GH, linear growth. Adult endocrinologists cannot rely on this end organ effect, and must therefore rely more heavily on GH stimulation tests. Corneli et al. [12] have shown that subjects with BMI $>30 \mathrm{~kg} / \mathrm{m}^{2}$ have a lower peak GH to GHRH + arginine than lean subject. This has recently been confirmed to be the case for the glucagon test (with normal response above $1 \mathrm{ng} / \mathrm{ml}$ ), presently widely used in the USA due to GHRH unavailability [13]. This has prompted the recommendation of different GH stimulation cutoffs based on BMI. However, while a BMI cutoff is used, an inverse correlation between BMI and GH peak seems to exist. Therefore, ideally, rather than cutoff, we would need a nomogram where continuous BMI values could be correlated to "normal" GH peak. Because GHD subjects in this work were significantly more overweight than non GHD (BMI $42.70 \pm 10.16$ vs. $38.02 \pm 7.11 \mathrm{~kg} / \mathrm{m}^{2} p<0.001$ ), it is possible (despite a negative multiple regression analysis) that worse obesity-rather than ES-was the main cause of reduced peak GH. Accordingly, significant weight loss reverses defects in 24-h spontaneous GH release profiles, basal IGF-I levels, and GH response to insulin-induced hypoglycemia, pointing to an acquired and potentially transient defect rather than a persistent anatomic disorder [14]. It has been suggested that waist circumference (WC) (rather than BMI) is the best predictor of GH response (at least in males), with a peak after arginine + GHRH that is reduced by $1.0 \mathrm{ng} / \mathrm{ml}$ for each $1 \mathrm{~cm}$ of waist circumference [15]. The GHD subjects reported by Lubrano et al. did have larger WC than normal $(128.90 \pm 18.81$ vs. $118.43 \pm 16.43 \mathrm{~cm}, \quad p<0.001)$. Although multivariate analysis did not seem to correlate GH peak with WC, it would be interesting to re-analyze the data adjusting the GH peaks according to the above-mentioned correction. Finally, it is my opinion that, in the absence of a gold standard for the diagnosis of GHD, any conclusion on a new cutoff for the GHRH + arginine test based on this work is premature.

In conclusion, while it would be tempting to consider GHD among the causes of obesity, until we have a more precise way to assess GH secretion in obese subjects that is accurately adjusted by obesity indexes (and preferably by gender and age), we will be always be left wondering what came first, obesity or GHD. That said, it is possible that GH therapy (replacement or pharmacological) may in the future prove to be a useful tool in at least some forms of apparently idiopathic obesity. To this end, randomized clinical trials are needed. Until then, the use of GH in adults should be reserved to approve indications [16].

Conflict of interest No funding was used for this work. The author has no conflict of interests related to the topic of this article.

\section{References}

1. A. Bartke, L.Y. Sun, V. Longo, Somatotropic signaling: tradeoffs between growth, reproductive development, and longevity. Physiol. Rev. 2013(93), 571-598 (2013)

2. A.A. Sakharova, J.F. Horowitz, S. Surya, N. Goldenberg, M.P. Harber, K. Symons, A. Barkan, Role of growth hormone in regulating lipolysis, proteolysis, and hepatic glucose production during fasting. J. Clin. Endocrinol. Metab. 93, 2755-2759 (2008) 
3. S. Savastano, C. Di Somma, L. Barrea, A. Colao, The complex relationship between obesity and the somatropic axis: the long and winding road. Growth Horm. IGF Res. 24, 221-226 (2014)

4. M.E. Molitch, D.R. Clemmons, S. Malozowski, G.R. Merriam, M.L. Vance, Evaluation and treatment of adult growth hormone deficiency: an Endocrine Society clinical practice guideline. J. Clin. Endocrinol. Metab. 96, 1587-1609 (2011)

5. A. Agha, J.P. Monson, Modulation of glucocorticoid metabolism by the growth hormone - IGF-1 axis. Clin. Endocrinol. (Oxf.) 66, 459-465 (2007)

6. J.D. Veldhuis, A. Iranmanesh, K.K. Ho, M.J. Waters, M.L. Johnson, G. Lizarralde, Dual defects in pulsatile growth hormone secretion and clearance subserve the hyposomatotropism of obesity in man. J. Clin. Endocrinol. Metab. 72, 51-59 (1991)

7. C. Lubrano, M. Tenuta, D. Costantini, P. Specchia, G. Barbaro, S. Basciani, S. Mariani, A. Pontecorvi, A. Lenzi, L. Gnessi, Severe growth hormone deficiency end empty sella in obesity: a cross sectional study. Endocrine (2015). doi:10.1007/s12020-0150530-0

8. M. Gasperi, G. Aimaretti, E. Cecconi, A. Colao, C. Di Somma, S. Cannavò, C. Baffoni, M. Cosottini, L. Curtò, F. Trimarchi, G. Lombardi, L. Grasso, E. Ghigo, E. Martino, Impairment of GH secretion in adults with primary empty sella. J. Endocrinol. Invest. 25, 329-333 (2002)

9. C.L. Deal, M. Tony, C. Höybye, D.B. Allen, M. Tauber, J.S. Christiansen, Growth Hormone in Prader-Willi Syndrome Clinical Care Guidelines Workshop Participants. Growth Hormone Research Society workshop summary: consensus guidelines for recombinant human growth hormone therapy in Prader-Willi syndrome. J. Clin. Endocrinol. Metab. 98, E1072-E1087 (2013)

10. D.E. Berryman, C.A. Glad, E.O. List, G. Johannsson, The GH/ IGF-1 axis in obesity: pathophysiology and therapeutic considerations. Nat. Rev. Endocrinol. 9, 346-356 (2013)
11. E. Gomes-Santos, R. Salvatori, T.O. Ferrão, C.R.P. Oliveira, R.D.C.A. Diniz, J.A.M. Santana, F.A. Pereira, R.A.A. Barbosa, A.H.O. Souza, E.V. Melo, C.C. Epitácio-Pereira, A. Alves, I.A.S. Oliveira, J.A. Machado, F.J. Santana-Júnior, J.A.S. Barreto-Filho, M.H. Aguiar-Oliveira, Increased visceral adiposity and cortisol to cortisone ratio in adults with congenital lifetime isolated $\mathrm{GH}$ deficiency. J. Clin. Endocrinol. Metab. 99, 3285-3289 (2014)

12. G. Corneli, C. Di Somma, R. Baldelli, S. Rovere, V. Gasco, C.G. Croce, S. Grottoli, M. Maccario, A. Colao, G. Lombardi, E. Ghigo, F. Camanni, G. Aimaretti, The cut-off limits of the GH response to GH-releasing hormone-arginine test related to body mass index. Eur. J. Endocrinol. 153, 257-264 (2005)

13. L.E. Dichtel, K.C. Yuen, M.A. Bredella, A.V. Gerweck, B.M. Russell, A.D. Riccio, M.H. Gurel, P.M. Sluss, B.M. Biller, K.K. Miller, Overweight/Obese adults with pituitary disorders require lower peak growth hormone cutoff values on glucagon stimulation testing to avoid overdiagnosis of growth hormone deficiency. J. Clin. Endocrinol. Metab. 99, 4712-4719 (2014)

14. M.H. Rasmussen, A. Hvidberg, A. Juul, K.M. Main, A. Gotfredsen, N.E. Skakkebaek, J. Hilsted, N.E. Skakkebae, Massive weight loss restores 24-hour growth hormone release profiles and serum insulin-like growth factor-I levels in obese subjects. J. Clin. Endocrinol. Metab. 80, 1407-1415 (1995)

15. H. Makimura, T. Stanley, D. Mun, S.M. You, S. Grinspoon, The effects of central adiposity on growth hormone $(\mathrm{GH})$ response to GH-releasing hormone-arginine stimulation testing in men. J. Clin. Endocrinol. Metab. 93, 4254-4260 (2008)

16. D.R. Clemmons, M. Molitch, A.R. Hoffman, A. Klibanski, C.J. Strasburger, D.L. Kleinberg, K. Ho, S.M. Webb, M.D. Bronstein, R. Bouillon, A. Ben-Shlomo, A.H. Hamrahian, P. Chanson, A.L. Barkan, G.R. Merriam, M.R. Blackman, R. Salvatori, Growth hormone should be used only for approved indications. J. Clin. Endocrinol. Metab. 99, 409-411 (2014) 